\title{
SCM DESIGN FOR WATER DISTRIBUTION WITH QFD APPROACH
}

\author{
Shamsuddin Ahmed, KIMEP, Shamsuddin_Ahmed@Yahoo.Com \\ Mujibul Haque, KIMEP, mmhaque@kimep.kz
}

\begin{abstract}
Distribution plan for a bottled drinking water company in the Central Asian Region is developed using Quality Function Deployment (QFD). The QFD explores the essential customer expectations as important information to construct an efficient distribution plan to augment responsive water distribution Supply Chain (SC). The significant SC characteristics those are necessary in meeting the customer expectations are identified, Using QFD. The water bottling plant and the distribution centre are located far from the city, where corporate and residential customers are located. Current distribution plan of the company is benchmarked to determine competitive advantage among other companies engaged in similar business. QFD identify that the routing plan needs restructuring to leverage SC response time. New locations of distribution centers in city are necessary to improve delivery time considering traffic congestion during rush hours. Algorithms to develop spatial distribution plans, with overlay map, using SC network design software are discussed. The delivery plan shows how the routing is developed using city map. The analysis also demonstrates how to benchmark SC performance.
\end{abstract}

Keywords: Quality function Deployment (QFD), Supply Chain, DSS, Service Design, Routing Algorithm, Benchmarking.

\section{INTRODUCTION}

L-Service is one of the leading companies that produce and distribute 19.9 liters bottled mineral water in central Asian region. The location of the water bottling factory and the distribution centre is far from the customer locations. Majority of the customers are located at least 12 kilometers away from distribution centre. Faced with stiff competition, growing number of customers, and delay in delivery time due to heavy road traffic all the time, affecting the existing time schedule. The L-service company is eager to find an immediate solution to avoid customer dissatisfaction. To address the issue, assessment of the current state is planned to identify the customer requirements and how the distribution scheme is weakening the business. To address the issues, QFD methodology is employed. In such pursuit, one immediate approach is to evaluate the existing locations and the distribution plan. In particular, the study explores new distribution centre location against the existing customer base. Traditionally, in the location research literature, minimizing the total transportation costs from central distribution centre to the customer base, the locations of the distribution centers are identified (Gill and Bhati, 2007; Khumawala, 1973, 1974). Under the general notion of reengineering, however, many companies realize that moving the production facilities and central distribution centre to market areas will not only reduce transportation costs, but also shorten and simplify the distribution channels to provide better service with lower inventories (Harmon 1993; Lopez, 1989). In this study the relocation of existing distribution centre entirely is not feasible, because L-Service Company is a producer of water as well as distributor. The current distribution centre exists in a place where the water source is located. Hence the location of plant is constrained and cannot be moved. As a matter of fact, by grouping the customer location as clustered zone and identifying new distribution center in that clustered zone serves the best in identifying solution to the problem. This may increase the setup cost initially but savings and customer loyalty is expected to rise as result of efficient distribution plan. Relocating new distribution centre near customer base, the delivery time is improved. This is accomplished by developing spatial distribution plan using a routing algorithm.

The QFD unveil how the existing services should improve or change owing to customer requirements (Lai, et al, 2006; Hari et al, 2007; Kim et al, 2007). To this end, a survey is planned to identify important customer needs and technical functions that are important to improve SC performance in the form of a QFD. The QFD determines what would satisfy customer requirements and how the customer needs are transformed into a final services design. The methodology encapsulates precise customer wants and classifies alternative solutions. The customer requirements are first integrated into a new product design matrix called (HoQ). The HoQ is a graphic procedure that defines the relationship between customer desires and product characteristics or service elements. The HoQ matrix is an expression that explains the relationship between the requirements of the customer; the what's list, and the design characteristics of the new product known as the how's list as shown in Figure 1.

\section{QUALITY FUNCTION DEPLOYMENT (QFD)}

Referring to Figure 1, the customer requirements, or, what's are the major competitive factors. Alternately, it implies what do prospective customer wants in a product (Raynor, 1994). The competitive scores in 
HoQ is the relative performance of a product. The design characteristics or how's of the product, are the diverse operational dimensions of the design, a customer require in a product or service. The middle portion of the matrix characterizes the interrelationship between the what's and the how's. This is often based on the panel or design team's judgments. The symbols, on the top of the matrix, indicate strong, medium or weak relationship, which are compared with customer requirements and customer importance list in matrix to populate with the data. The bottom part of the matrix is technical assessment of the product. It epitomizes the absolute importance of each design characteristic and is ranked with relative importance. The triangular roof of the house captures correlation information that either represents positive or negative association between the various design characteristics (Büyüközkan et al., 2004).

The study attempts to define the customer's desires into the customer's own voice and identifies the areas of improvement in distribution strategy. Classifying the customer requirements and translating them into technical functions, the study progressively categorizes how the customer concern would be accomplished. QFD has emerged as an effective tool in designing product and services, identifying What's and How's of product attributes from customer viewpoint. It is a multifactor measurement procedure that integrates considerable decision-making components. In QFD, the first step is to identify the customer(s) for LService. Some diagnostic questions follow such as: who wants the mineral water? Who will process/produce the product and how? Who will use the mineral water? Customer requirements are determined in second step. A list of all the customer requirements and constraints are produced in customers' own words. Functional requirements are statements of the specific performance of the design/specifications, for instance, what the mineral water and distribution service should do. The types of requirements vary from basic, performance to excitement needs. In basic needs the requirements are so fundamental that they are often not expressed, however they are crucial and must be identified, otherwise the customers are dissatisfied. The performance needs are basic requirements, which provide increased satisfaction as performance improves, such as customer query handling, accuracy of invoices, reliable delivery, and so on. While, excitement-need generates immediate happiness. Creation of excitement features will differentiate the product and service from market competition. Prioritization of customer requirements is the third step, where each requirement should be listed in order of importance. At this stage, the design team decides how much effort, time, and money should be invested to achieve the requirement. The competitive benchmarking is the fourth step. Benchmarking provides standard, or point of reference and range, that can be used to judge quality, value, and performance. It provides a perspective on what the best-in-class product and what makes it so. Final outcomes from benchmarking include discoveries about where the product and industry appear to be headed in the future with current trends. Competitive benchmarking thus identifies relative position of the competitor's position against customer requirements by testing, analyzing, reverse-engineering competitor's products or services. In sequence, step five translates the customer requirements into technical specifications. The list of general requirements, customer's vision, and market information are put together to conceptualize technical requirements. This helps in achieving low cost, reliable, strong, and sustainable development (Vollerthun, 2002). In step six, the technical targets for design specifications are determined. With reasonable targets for each of the design specifications, the study determines how the service meets the technical targets. Mind however, targets are not one time predicament; they can change as the product or service develops. The technical targets must be quantifiable and/or testable to be practical (Pradad, 2001). To assess the current status of the company's distribution policy, the routing and distribution plan is also evaluated.

\section{Data collection}

To populate the HoQ matrix and identify target element to improve water delivery, several methods are used to collect data. Methods include interviewing neighbors, friends, who order bottled water and express concern for the services rendered to them. A discussion with sales manager of the L-Service Company provides information about annual sales, competitors' information, pricing related data and existing route scheduling methods. The corporate web site is visited to collect general information about the company. The chief accountant is consulted to get additional information about the data processing. Customers are contacted to learn how the order processing is handled. The customers place order either by telephone call or request via web. In addition, the delivery of water follow regular schedule for repeat customers and large corporate clients.

During the meeting with sales manager it became clear that the city zones are divided into number of clusters for water delivery. Each truck has its own route and the list of addresses for delivery in a certain cluster. Currently the company defines twenty-three clusters for water delivery.

To assess the water demand in corporate offices, we consider water consumption about 0.5 liters per person per day, or approximately 10 liters per month, excluding soft drink consumptions. Twenty working days are assumed in a month. In other words the supply of water in one office with 50 employees would make 
an annual profit of 1900-2500 dollars with current market value. The computation excludes the earnings due to renting or selling of the special water dispensers. At the moment the L-Service Company identifies 3000 corporate and small office customers in city. The market research estimates 40 million liters of bottled water in city for the office consumptions. The number of companies producing bottled water is growing at 35 to $40 \%$ per year in central Asia. In year 2004 the LService Company produced 320 million liters of bottled water. The consumption of bottled mineral water per person in central Asia is approximately 19 liters.

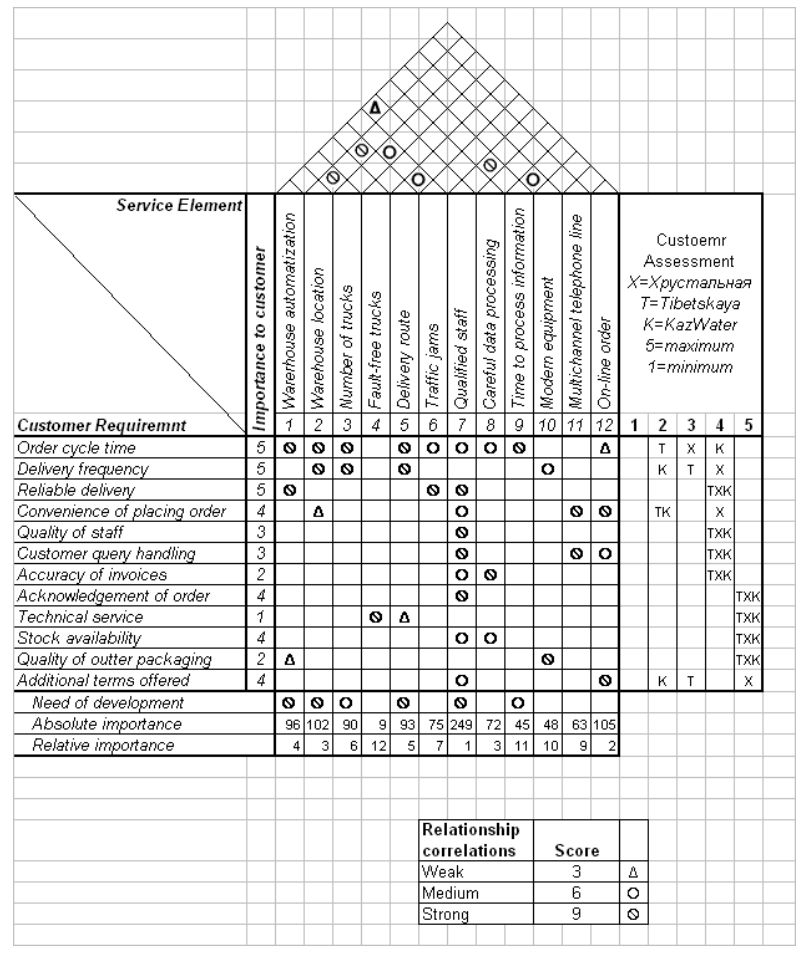

Figure 1 House of quality

\section{House of Quality}

The information gatheherd from the survey is listed in HoQ as shown in Figure 1. The HoQ shows order cycle time, delivery frequency and reliable delivery as the most important customer requirements. The strong relationships of the HoQ are determined with the service elements, such as warehouse automation, warehouse location, and number of trucks, delivery routes, and information processing time. That's why these requirements need immediate attention from the L-Service Company. The correlation matrix shows the strong link between warehouse location and delivery route, as well warehouse location and number of trucks.

To benchmark the L-Service Company against its competitors, the management provided data to assist in developing the HoQ matrix. The potential competitors are compared with the product and services they offer to a customer and each competitor is ranked with objective and subjective measure. The following scales are used to benchmark the companies based on competition's product as perceived by the customer requirements.

$1=$ the design does not meet the requirement

$2=$ the design meets the requirement slightly

$3=$ the design meets the requirement somewhat

$4=$ the design meets the requirement mostly

$5=$ the design completely meets the requirement

The scores of the HoQ matrix are computed for interpretation. For example, the absolute score of the service element defined as Warehouse location or Distribution center location contains score of 102 computed as $\sum$ (Weights of customer requirements on importance to customers) $\mathrm{x}$ (Score of the service element with respect to customer requirement). The score is $9 \times 5+9 \times 5+4 \times 3=102$. The relative importance of this factor is computed as 3 and hence ranked third among the other service elements. The importance to customers is weighted according to its value perceived by the customers.

The analysis of the competitors in business revealed that the position of L-Service Company is on the same level with regards to major customer requirements and takes the leading position in Additional terms offered (discounts, special offers, presents) and Convenience of placing order (on-line order, multi-channel telephone lines). But the Order cycle time needs to be improved.

The HoQ analysis identifies that the Warehouse location, Warehouse automation, Delivery route and Qualified staff attributes or functions need further development and improvement. Most of these problems can be mitigated, using operational procedure, information systems, process improvement and quality and HR management in resolving qualification of staff or qualified staff issues. The benchmark identify that the L-service company has fair chance to improve on the first few customer requirement functions with adequate training to its employees.

\section{Data analysis}

The analysis suggests that there are needs for additional distribution centers. The cost may increase substantially due to capital cost to deliver the service at the same level; however the quality may improve in response time. One possible alternative is to lease new trucks and trailer. In order to operate warehouses in new locations, the management should recognize the interdependence between warehouse location decisions, inventory decisions, customer service, and demand. The demand refers to the potential value of 
sales. The analysis of these relationships is classed into three segments namely: interdependence between warehouse location and inventory decisions; effect of warehouse location, inventory decisions on customer service and delivery response time; and effect of customer service on demand (Gao, 1992; Speranza and Ukovich, 1996). The analysis focuses in main customer requirements that are necessary to improve customer service quality.

\section{RESPONSIVE SCM}

The information rooted in HoQ requires appropriate organization in visualizing QFD and developing a feasible service system. Usually, QFD is applied in early stages of the design phase, so that the customers' wants are incorporated into the final product. Besides, it can be used as a planning tool, for continuous service improvement, since it identifies the most important areas in which the effort should focus in relation to the technical capabilities. In producing bottled mineral water and distributing it to customers, several functions interact, namely, marketing, manufacturing, distribution and other ancillary services. The water distribution is a primary service for the company and all concerned personnel and interest group view it important. Based on the analysis of customer requirements, it is understood that the distribution is an important issue due to time window constraint, delivery capacity, and traffic congestion. The distribution and delivery problem is inherently complex to solve (Magnanti, 1981; Osman and Wassan, 2002; Golden et al., 1977; Bodin and Golden, 1981; Süral and Bookbinder, 2003; Francis et al., 2007; Baltz et al., 2007; Chao et al., 1995). All stakeholders are interested in quick delivery and reduction in order cycle time. It is feasible to set up a central distribution centre, thus optimizing the routing and delivery schedule. Accordingly, the study suggests dividing the city into four zones clustered with a central distribution centre and uniform delivery load to each location or zone. Trucks with $500 \mathrm{~kg}$ capacity are suggested to employ for more number of trips in small zones with heavy demand instead of trucks with $4500 \mathrm{~kg}$ capacity to reduce the delivery response time. Customers need product delivery in a specified time window; this suggests a responsive supply chain design requirement. Improved distribution schedule is required to addresses water distribution, in case of heavy traffic congestions in city. The problem inherently requires flexible water distribution plan, delivery and scheduling policy to the customers. The task becomes more difficult as additional constraints are placed on the problem such as time windows, multiple trucks with different capacity, and different speeds are a few of the practical considerations that need to be given to route design. Among many approaches; Jansen, 1993; Agrawal, et al., 1989; Anily, 1996; Christofides, Mingozzi, and Toth, 1981; suggested vehicle routing methods to resolve such complex problems. However, sweep method (Chopra, 2007) is convenient to address the issue. The sweep method is simple for large problem sizes. When programmed into software, it solves rapidly without requiring enormous amounts of computer memory. The percentage of errors is about $10 \%$, but it is acceptable for L-Service Company, because the results needs to be customized in order to fit the local condition of the heavy traffic on road and bottlenecks during rush hours in city. Delivery and dispatches are often faced with generating quick routing patterns within an hour of receiving a customer call with specific demand and time requirements. The main phases of sweep algorithm for water distribution plan are:

1. Locate all customer locations including the distribution centre on an overlay map or grid.

2. Extend a straight line from the distribution centre in a chosen direction. Rotate the line clockwise or counterclockwise, until it intersects a stop or customer base. Analyze if the inserted stop should be included on the route provided that the assigned vehicle for water delivery is sufficient with capacity. If not, proceed with the line rotation until next stop is intersected. Again, identify, if the cumulative volume is contained by the vehicle capacity.

3. Within each route, sequence the stops to minimize delivery time using distance information. The sequencing may be accomplished by applying the teardrop method or by using any algorithm that solves the route optimization problem. Quite often, the routing and delivery sequence would look like an ellipse approximately. A logistic planner, who designs the truck delivery sequence, can go a long way toward developing good truck routes and schedules by applying the following guideline:

a.) Assign a truck with stop volumes that are in the closest proximity to each other. Truck routes should be formed around clusters of stops that are nearest each other in order to minimize the inter-stop travel between them.

b.) Stops on different days should be arranged to produce tight clusters. When stops are to be served during different days of the week, the stops should be segmented into separate routing and scheduling problems for each day of the week.

c.) Build the routes beginning with the farthest stop from the distribution centre. Building stop sequence clusters around the farthest stop from the distribution centre and then work back toward the distribution centre to construct 
efficient routes. The customer location is geocoded by a linear grid overlay with a mapscaling factor $62 \mathrm{~m}$. The customers are clustered starting with the farthest customer and then adding customers by progressively moving toward the distribution centre.

d.) Stops should be sequenced so that no path of the route crosses and the route appears to have a teardrop shape.

e.) The most efficient routes are built using the largest vehicles available. Ideally, using a vehicle large enough to handle all stops in one route will minimize total distance, or time, or cost traveled to serve the stops.

f.) Pickups should be mixed into delivery routes.

g.) A stop that is removed from a route cluster is a good candidate for an alternate means of delivery. Stops that are isolated from the stop clusters, especially those with low volume, are served when delivery time is high.

h.) Avoid narrow time window restrictions for stop sequence.

Table 1: Sweep Algorithm

Using the step number 3 of the algorithm as outlined in table 1 , the route is constructed. The method of route construction is shown in Figure 2. For a single zone thus the route is constructed as displayed in Figure 3.

\section{Location of new distribution centre}

The other step is to consider the location of new warehouses (Sherali, 2000). QFD matrix points to water distribution management. To analyze the customer concern, evaluation of distribution centre is recommended. Location planning method (Tompkins et al. 2003) is a technique that evaluates the existing situation, by weighted movements of bottled water in a geographic area based on frequency of load distribution and distances from the customer base. The following steps are recommended. The transportation volume to each distribution point and geographic location of the customer base is identified in Cartesian coordinate system. Using centre of gravity method, the distribution centre location is determined or evaluated against the customer base. The location of the distribution centre in $x$ coordinate is $\sum\left(\mathrm{x}_{\mathrm{i}} \mathrm{q}_{\mathrm{i}}\right) / \sum \mathrm{q}_{\mathrm{i}}$ and in $\mathrm{y}$ coordinate is $\sum\left(\mathrm{y}_{\mathrm{i}} \mathrm{q}_{\mathrm{i}}\right) / \sum \mathrm{q}_{\mathrm{i}}$, where, $\mathrm{q}_{\mathrm{i}}=$ volume of water to be delivered to destination $\mathrm{i}$, while, $\mathrm{x}_{\mathrm{i}}=\mathrm{x}$ coordinate of customer base $i$, and $y_{i}=y$ coordinate of customer base i. Using Blue zone the computation of the warehouse location is shown using the center of gravity method. The percentage of sales of six locations of Blue zone derived form the total sales and coordinates of delivery points computed as the average number of customer locations are shown in Table 1.

$\begin{array}{cccc}\text { Destination } & \text { Sales \% } & \text { X } & \text { Y } \\ \text { D1 } & 14 \% & 6 & 19 \\ \text { D2 } & 44 \% & 13 & 17 \\ \text { D3 } & 13 \% & 20 & 22 \\ \text { D4 } & 8 \% & 5 & 6 \\ \text { D5 } & 8 \% & 14 & 7 \\ \text { D6 } & 13 \% & 23 & 12\end{array}$

Table 1. Delivery points coordinates

The computed delivery points are geo-coded by a linear grid overlay map. The position of the distribution centre computed as $\mathrm{X}=14$ and $\mathrm{Y}=16$. This location in city is the Seifullina-Mametovoi road crossing and therefore a feasible location at coordinate $\mathrm{X}=12.5$ and $\mathrm{Y}=12$ is suggested. The location is an industrial zone and hence it is appropriate for a new distribution centre. Similar procedure is followed to locate the distribution centers in other areas.

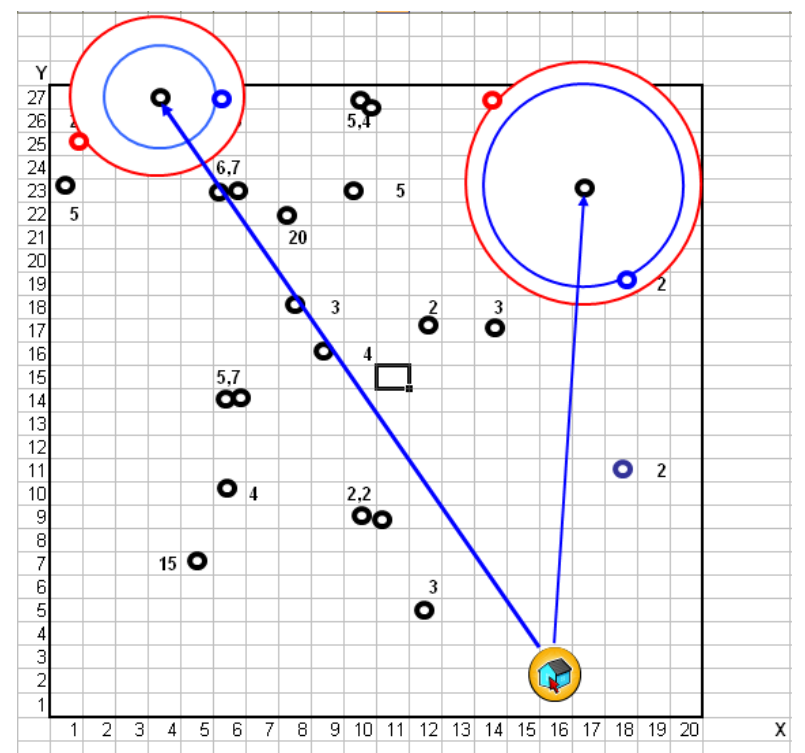

Figure 2. Scheme for truck routing

Based on the analysis it is feasible for the L-Service Company to locate a new warehouses in Raimbeka Seifullina, Kosmonavtov - Gabdullina, Utegen Batyra - Tolebi districts.

\section{Route optimization}

The next step is to optimize the delivery routes from new distribution centre (Eskigun, et al. 2006). Figure 3 shows the truck route. The position of the blue arrows shows the direction of a truck during a typical morning delivery. The route is developed by sweep method, as described in Algorithm listed in Table 1 with overlay 
spatial map-positioning $\mathrm{l}$ scheme. In addition, a vehicle routing algorithm (Ahmed, 2006) is employed to construct the best possible route sequence.

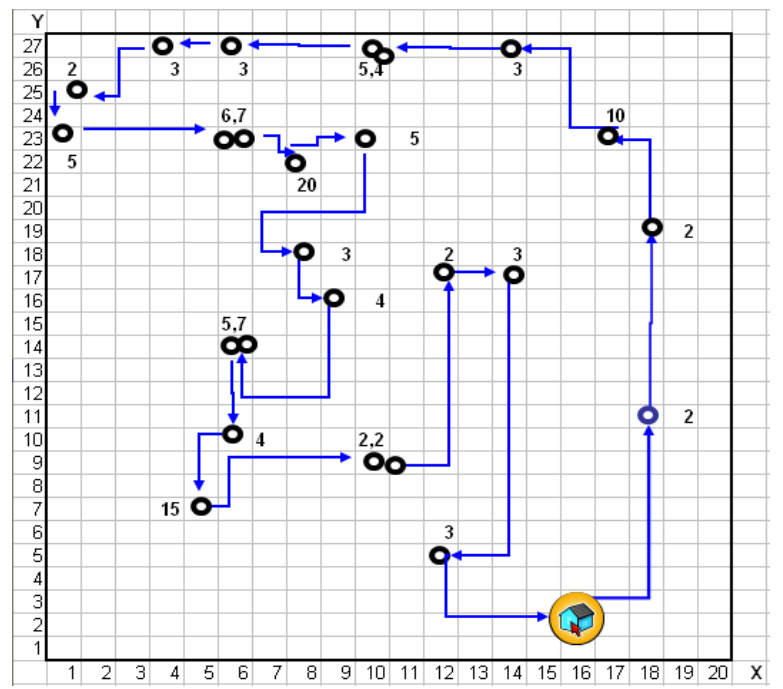

Figure 3. Scheme of truck route for Blue zone

\section{CONCLUSIONS}

The QFD is an important tool in designing the service system. The HoQ identifies the limitation of the current water distribution plan. It also illustrates what are the critical factors that need to be resolved in order of priority. A spatial distribution plan and routing design is shown in overlay map. The routing plan is constructed employing an algorithm. The spatial routing shows how the delivery and distribution is planned. The application of QFD illustrates how a service can be benchmarked and how to improve SC logistics planning using water distribution as an example in central Asia.

\section{REFERENCES}

1. Ahmed, Shamsuddin. "A Near Optimal Network Based Vehicle Routing Problem Formulation", Editors: C.H Dagli, A.L. Buckak, D.L. Enke, M.J. Embrechts, O. Ersoy, ASME Press Series on intelligent systems, Vol. 16, (ISBN 0-7918-02566), pp 835-840, New York, USA, 2006.

2. Amihud Hari, Joseph E. Kasser, Menachem P. Weiss (2007). How lessons learned from using QFD led to the evolution of a process for creating quality requirements for complex systems, Systems Engineering, Volume 10, Issue 1, Pages: 45-63.

3. Andreas Baltz, Devdatt Dubhashi, Anand Srivastav, Libertad Tansini, Sören Werth (2007). Probabilistic analysis for a multiple depot vehicle routing problem, Random Structures and Algorithms, Volume 30, Issue 1-2, Pages: 206225.
4. Andreas Vollerthun (2002). Design-to-market integrating conceptual design and marketing, Systems Engineering, Volume 5, Issue 4, Pages: 315-326.

5. Avninder Gill 1, M. Ishaq Bhatti (2007). Optimal model for warehouse location and retailer allocation, Applied Stochastic Models in Business and Industry, Published Online: 3 Jan 2007.

6. B. L. Golden, T. L. Magnanti, H. Q. Nguyen (1997). Implementing vehicle routing algorithms, Networks, Volume 7, Issue 2, Pages: 113-148.

7. Basheer M. Khumawala (1973). An efficient heuristic procedure for the uncapacitated warehouse location problem, Naval Research Logistics Quarterly, Volume 20, Issue 1, Pages: 109-121.

8. Basheer M. Khumawala (1974). An efficient heuristic procedure for the capacitated warehouse location problem, Naval Research Logistics Quarterly, Volume 21, Issue 4, Pages: 609-623.

9. Biren Prasad (2001). Total value management - a knowledge management concept for integrating TQM into concurrent product and process development, Knowledge and Process Management, Volume 8, Issue 2, Pages: 105-122.

10. Chopra, S., Meindl, P. (1997). Supply chain Management, Prentice Hall, New Jersey, USA.

11. Erdem Eskigun, Reha Uzsoy, Paul V. Preckel, George Beaujon, Subramanian Krishnan, Jeffrey D. Tew (2006). Outbound supply chain network design with mode selection and lead time considerations, Naval Research Logistics, Volume 54, Issue 3, Pages: 282-300.

12. Gülçin Büyüközkan, Tijen Ertay, Cengiz Kahraman, Da Ruan (2004). Determining the importance weights for the design requirements in the house of quality using the fuzzy analytic network approach, International Journal of Intelligent Systems, Volume 19, Issue 5, Pages: 443-461.

13. Haldun Süral, James H. Bookbinder (2003). The single-vehicle routing problem with unrestricted backhauls, Networks, Volume 41, Issue 3, Pages: 127-136.

14. Hanif D. Sherali, Taehyung Park (2000). Discrete equal-capacity p-median problem, Naval Research Logistics, Volume 47, Issue 2, Pages: 166-183.

15. Ho, Peng-Kuan, Perl, Jossef, (1995). Warehouse location under service-sensitive demand, Journal of Business Logistic.

16. Ibrahim H. Osman, Niaz A. Wassan (2002). A reactive tabu search meta-heuristic for the vehicle routing problem with back-hauls, Journal of Scheduling, Volume 5, Issue 4, Pages: 263-285.

17. I-Ming Chao, Bruce L. Golden, Edward Wasil (1995). An improved heuristic for the period vehicle routing problem, Networks, Volume 26, Issue 1, Pages: 25-44. 
18. Kazuyoshi Hidaka, Hiroyuki Okano, Simulationbased approach to the warehouse location problem, Tokyo Research Laboratory, IBM Japan Ltd.

19. Klaus Jansen (1993). Bounds for the general capacitated routing problem, Networks, Volume 23, Issue 3, Pages: 165-173.

20. Kwang-Jae Kim, Deok-Hwan Kim, Dae-Kee Min (2007.) Robust QFD: framework and a case study, Quality and Reliability Engineering International, Volume 23, Issue 1, Pages: 31-44.

21. Lawrence Bodin, Bruce Golden (1981). Classification in vehicle routing and scheduling, Networks, Volume 11, Issue 2, Pages: 97-108.

22. Li-Lian Gao, E. Powell Robinson Jr. (1992). A dual-based optimization procedure for the twoechelon uncapacitated facility location problem, Naval Research Logistics, Volume 39, Issue 2, Pages: 191-212.

23. M.G. Speranza, W. Ukovich (1996). An algorithm for optimal shipments with given frequencies, Naval Research Logistics, Volume 43, Issue 5, Pages: 655-671.

24. Michael E. Raynor, (1994). The ABCs of QFD: formalizing the quest for cost-effective customer delight, National Productivity Review, Volume 13, Issue 3, Pages: 351-357.

25. Nicos Christofides, A. Mingozzi, P. Toth (1981). State-space relaxation procedures for the computation of bounds to routing problems, Networks, Volume 11, Issue 2, Pages: 145-164.
26. Peter Francis, Karen Smilowitz, Michal Tzur (2007). Flexibility and complexity in periodic distribution problems, Naval Research Logistics, Volume 54, Issue 2, Pages: 136-150.

27. Rigoberto A. Lopez, Nona R. Henderson (1989). The determinants of location choices for food processing plants, Agribusiness, Volume 5, Issue 6, Pages: 619-632.

28. Ronald H. Ballou, P.L. 1999, Business Logistics Management, Prentice Hall

29. Shoshana Anily (1996). The vehicle-routing problem with delivery and back-haul options, Naval Research Logistics, Volume 43, Issue 3, Pages: 415-434.

30. T. L. Magnanti, (1981). Combinatorial optimization and vehicle fleet planning: Perspectives and prospects, Networks, Volume 11, Issue 2, Pages: 179-213.

31. Tompkins, J.A., White, J.A., Bozer Y.A., Tanchoco, J.M.A. (2003). Facilities Planning, 3rd Edition, John Wiley, NJ, USA.

32. Xin Lai, Kay-Chuan Tan, Min Xie (2007). Optimizing product design using quantitative quality function deployment: a case study, Quality and Reliability Engineering International, Volume 23, Issue 1, Pages: 45-57.

33. Yogesh Agarwal, Kamlesh Mathur, Harvey M. Salkin (1989). A set-partitioning-based exact algorithm for the vehicle routing problem, Networks, Volume 19, Issue 7, Pages: 731-749. 